\title{
Kinetic study of negative dry-film photoresists
}

\author{
A. K. Diby ${ }^{1,2}$, V. Yu. Voytekunas ${ }^{1,3}$, M. J. M. Abadie ${ }^{1,4 *}$ \\ ${ }^{1}$ Laboratory of Polymer Science \& Advanced Organic Materials - LEMP/MAO, CC 021, Université Montpellier II, Place \\ Bataillon, 34095 Montpellier Cedex 05, France \\ 2Université Cocody d'Abidjan, Abidjan, Côte d'Ivoire \\ ${ }^{3}$ Singapore Institute of Manufacturing Technology - SIMTech, 71 Nanyamg Drive, 638075, Singapore \\ ${ }^{4}$ School of Materials Science \& Engineering, Nanyang Technological University, 50 Nanyang Avenue, 639798, Singapore
}

Received 1 June 2007; accepted in revised form 9 August 2007

\begin{abstract}
Thanks to the differential photocalorimetry technique DPC, characteristics of negative photoresists (Riston ${ }^{\circledR}$ PM 215 and Riston ${ }^{\circledR}$ MM 140, 1 mil or $25.4 \mu \mathrm{m}$ thickness) to be developed in nonorganic aqueous medium) used in microlithography are highlighted. The photoreactivity (being evaluated by DPC) of the matrix polymer involved in these Riston ${ }^{\circledR}$ is critical for ensuring good lithographic performance. The influence of temperature and irradiation intensity on kinetic parameters such as the enthalpy of reaction $\Delta H$, the time of induction $\left(I_{t}\right)$, the conversion rate to the maximum peak (RPM), the coefficient rate of the reaction $(k)$, the conversion rate $\alpha$, and the polymerization rate $R_{p}$ were studied.

All the results highlights not only the strong differences between the two Riston ${ }^{\circledR}$ studied, but also the great reactivity of Riston ${ }^{\circledR}$ PM 215 compared to Riston ${ }^{\circledR}$ MM 140.
\end{abstract}

Keywords: thermosetting resins, photoresists, differential photocalorimetry, kinetics, photoreactivity

\section{Introduction}

The explosive growth in performance of semiconductors devices has been fueled in part by advances in microlithography, which in turn fueled similar advances in photoresist technology [1]. The ability to continually shrink the feature size and improve the performance has occurred because of advancements in materials. Tremendous advances have been made in the development of negative resist systems. Their sensitivity, ease of chemical modification, and low cost have made them the materials of choice for both Printed Wiring Boards circuitry industry and Printed Circuit Boards industry, and they are being continually improved to provide greater resolution, ease of processing, and improved physical and thermal properties. For semiconductor industry, it has been necessary to provide negative resists to meet the ever-increasing circuit density requirements for every new generation of semiconductors devices.

Epoxy materials are attractive alternatives, since there are a large variety of epoxidized polymers available in both solid and liquid form. These materials generally offer excellent adhesion to semiconductor surfaces, good sensitivity, and low cost. The ever increasing complexity of integrated circuits multi-layers printed circuits (Ultra Large Scale Integration) and the fact that the epoxy based photoresists cannot be easily stripped after etching require new photosensitive dry film photopolymers such as DuPont Riston ${ }^{\circledR}$ Dry Film Resists. Dry film resist has numerous advantages such as good conformability, excellent adhesion on any substrate, no liquid handling due to absence of solvent, excellent thickness uniformity over the whole wafer, no formation of edge beads and low exposure energy [2].

*Corresponding author, e-mail: marc@ntu.edu.sg

(c) BME-PT and GTE 
The aim of the present study involves the characterization of new Riston ${ }^{\circledR}$ products. The effect of some factors on the rate of crosslinking and degree of conversion were assessed.

A series of Dry Films (1 mil thickness $0.0254 \mathrm{~mm}$ ), used as received, were evaluated as negative photoresist and characterized via free radical polymerization technique by DPC. Specimens were prepared by casting polymer films onto alumina plates (of diameter equal to $6 \mathrm{~mm}$ ).

\subsection{Photolithography}

Lithographic technology has been based on projecting an optical image of a device onto a resist in order to record the image for subsequent processing steps. Photolithography is the process of transferring geometric shapes onto the substrate (silicon wafer, pyrex, metal, ceramic).

When the image is projected onto the wafer, the photoresist materials undergo some light-sensitive chemical reactions, which cause the regions exposed to light to be either more (positive photoresist) or less (negative photoresist) susceptible to chemical etch. The resist is then 'developed' by immersion in a developer, which removes either the exposed (positive-tone) or the unexposed (negative-tone) photoresist. The resulting wafer then has a pattern coating on its surface. The pattern can then be etched into the underlying wafer by either a wet chemical etch or a plasma etch. When the resist image is transferred into the substrate by etching and related processes, the resist film that remains after development serves as a protective mask. The resist film must withstand the etchant and protect the underlying substrate while the bared areas are being etched. The remaining resist film is finally stripped, leaving an image of the desired circuit in the substrate.

\subsection{Photoresist}

Photoresist is a complex organic mixture of polymers and low-molecular weight additives that serves as light-sensitive template for manufacturing semiconductor integrated circuits. These polymers with a combination of properties such as high photosensitivity, good solubility, the ability to form films, good thermal stability, resistance towards solvent after crosslinking, resistance towards plasma and etching agents, are very important for practical use as negative photoresist materials. Resist transparency is a dominant factor in the choice of resist materials.

Exposure to the UV light causes the negative resist to become polymerized, and more difficult to dissolve. Indeed, when exposed to UV light in the range from 200 to $300 \mathrm{~nm}(4$ to $6 \mathrm{eV}$ ) the polymers form 'radical species' which can result in crosslinking, increased molecular weight, insolubilization, and film embrittlement [3]. The insolubilization can be achieved by using materials which, upon UV exposure, are photochemically rearranged to form new insoluble products. To increase molecular weight, photoinitiators are generally used.

\section{Experimental procedures}

\subsection{Materials}

Because of environmental concerns, a set of new resists were investigated to try to enhance the process latitude, reduce the manufacturing cost of resists and to meet safety requirements in a manufacturing environment. As such, DuPont Printed Circuit Materials supplied two types of Riston ${ }^{\circledR}$ which requires further characterization:

- Riston ${ }^{\circledR}$ MultiMaster MM 100 Series: a 'general purpose' dry film for acid and alkaline etch, copper, tin, nickel and gold plating,

- Riston ${ }^{\circledR}$ PlateMaster PM 100 Series: negative working, aqueous processable dry film photoresists. Specially designed for pattern plating applications on scrubbed and unscrubbed electroless copper and direct surfaces, it is functional in acid etching and suitable for some nickel/gold plating applications with fine line capability and wide exposure latitude.

The resist formulation, a thin film 'dry', is sandwiched between a polyolefin sheet and a polyester base, rolled up on a support core.

\subsection{Method}

The analysis of the photoreactivity has been perfomed by Differential Scanning Photocalorimeter (DPC), method widely described in [4]. Note that the technique is based on heat produced during all polymerization or crosslinking process, when the photoreactive compound is irradiated.

The exotherm of the curve leads to assess some kinetic paramteres such as: 
- enthalpy of the photochemical reaction $(\Delta H)$,

- induction time $\left(I_{t}\right)$ of the system corresponding to the consumption of $1 \%$ of monomer. In practice, it gives a good information of the photo reactivity of the film; the lower the induction time, the higher the reactivity of the photosensitive layer,

- resin reacted at maximum peak (RPM),

- percentage of conversion (degree of conversion $\alpha)$,

- coefficient of rate $k$ given by Sestak and Berggren equation, see Equations (1) and (2) [5]:

$R_{T}=-\frac{\mathrm{d} \alpha}{\mathrm{d} t}=k(T) \alpha^{m}(1-\alpha)^{n}$

with

$k(T)=Z \exp \left(-\frac{E_{a}}{R T}\right)$

where $m$ and $n$ the oder of initiation and propagation respectively, $E_{a}$ the activation energy of the crosslinking reaction.

The specimen of about $1 \mathrm{mg}$ is light-cured with UV light of intensity of $1.2 \mathrm{~mW} / \mathrm{cm}^{2}, 2.2 \mathrm{~mW} / \mathrm{cm}^{2}$ and $3.3 \mathrm{~mW} / \mathrm{cm}^{2}$ respectively. The measurements are carried out in air atmosphere. The sample analyzed is peeled out from polyethylene sheet, sticked directly to the pan, the upper layer being protected by the polyethyleneterephthalate film. This geometry of the sample allows preventing the sample from air, inhibitor of radical polymerization.

\section{Results and discussion}

\subsection{Kinetic parameters}

\subsubsection{Effect of intensity I of the irradiation}

The results representing evolutions of these parameters, according to intensity $I$, are consigned in Table 1 for Riston ${ }^{\circledR}$ MM 140 and Riston ${ }^{\circledR}$ PM 215. The Table 1 shows that intensity $I$ of the irradiation in the range of 1 to $3 \mathrm{~mW} / \mathrm{cm}^{2}$ does not have very significant effect on the kinetic parameters such as $\Delta H, \mathrm{RPM}, I_{t}$; however, the coefficient rate $k$ increases with the intensity. In addition one observes a greater reactivity for Riston ${ }^{\circledR}$ PM 215 (larger values of $\Delta H, k$, RPM and smaller value of $I_{t}$ ).

According to the nature of Riston ${ }^{\circledR}$, it is noted that the variation of the enthalpy of reaction is not very sensitive for the two Ristons and a slight difference appears for the time of induction. Significant differences appear in the case of the percentage of conversion to the maximum peak (RPM) and of the coefficient rate $k$. These last two parameters of Riston ${ }^{\circledR}$ PM 215 are higher than those of Riston ${ }^{\circledR}$ MM 140. That is probably due to the nature of their initial composition related to the specificity of their use. Although the composition of these samples is confidential (by DuPont Technologies) and therefore unknown, we can emphasise that the different reactivity observed for the two Ristons ${ }^{\circledR}$ is probably due to the chemical structure of the (meth)acrylate used, especially the presence of flexibilizer along the chain bearing the (meth)acrylate function which makes it more reactive. For example the use of triacrylate product such as trimethylolpropane-tri(ethyleneoxyde)acrylate [TMPT(EO)A] compared to trimethylolpropane-triacrylate [TMPTA] or a mixture TMPTA/TMPT(EO)A could explain the differences observed. The presence of oxygen of the ethyleneoxide structure $-\mathrm{O}-\mathrm{CH}_{2}-\mathrm{CH}_{2}-$ linked to the acrylate function for TMPT(EO)A gives more flexibility to the chain and therefore permits a better reactivity of the acrylate function. This structure-property relationship could explain why Riston ${ }^{\circledR}$ PM 215 is more photosensitive than Riston $^{\circledR}$ MM 140.

\subsubsection{Effect of temperature of polymerization}

Tables 2 and 3 demonstrate that the temperature of polymerization constitutes a significant parameter and strongly affects the kinetic behaviour of the crosslinking polymerization of the photoresists.

Table 1. Comparative values of the kinetic parameters of the Ristons ${ }^{\circledR}$ studied ( 1 mil thickness $-0.0254 \mathrm{~mm}$ )

\begin{tabular}{|c|c|c|c|c|c|c|c|c|}
\hline & \multicolumn{4}{|c|}{ Riston $^{\circledR}$ MM 140 } & \multicolumn{4}{c|}{ Riston $^{\circledR}$ PM 215 } \\
\hline $\mathbf{I}\left[\mathbf{m W} / \mathbf{c m}^{2}\right]$ & $\Delta \mathbf{H}[\mathbf{J} / \mathbf{g}]$ & $\mathbf{I}_{\mathbf{t}}[\mathbf{s}]$ & $\mathbf{R P M} \boldsymbol{\alpha}[\%]$ & $\mathbf{k ~}\left[\mathbf{m i n}^{-1}\right]$ & $\Delta \mathbf{H}[\mathbf{J} / \mathbf{g}]$ & $\mathbf{I}_{\mathbf{t}}[\mathbf{s}]$ & $\mathbf{R P M}[\%]$ & $\mathbf{k}[\mathbf{1} / \mathbf{m i n}]$ \\
\hline 1.2 & $53 \pm 4$ & $2.9 \pm 0.1$ & $6.9 \pm 0.3$ & $9.2 \pm 0.2$ & $60 \pm 4$ & $2.1 \pm 0.1$ & $9.8 \pm 0.3$ & $12.6 \pm 0.2$ \\
\hline 2.2 & $53 \pm 4$ & $2.9 \pm 0.1$ & $6.2 \pm 0.3$ & $9.7 \pm 0.2$ & $59 \pm 4$ & $1.9 \pm 0.1$ & $9.7 \pm 0.3$ & $13.8 \pm 0.2$ \\
\hline 3.3 & $58 \pm 4$ & $2.9 \pm 0.1$ & $6.3 \pm 0.3$ & $10.3 \pm 0.2$ & $62 \pm 4$ & $1.8 \pm 0.1$ & $9.6 \pm 0.3$ & $16.8 \pm 0.2$ \\
\hline
\end{tabular}

( $\Delta H$ enthalpy, $I_{t}$ induction time, $R P M$ resin reacted at peak maximum, $k$ coefficient of rate) 
Table 2. Effect of measurement temperature on kinetic parameters, @ I=3.3 mW/cm ${ }^{2}$, for Riston ${ }^{\circledR} \mathrm{MM} 140$

\begin{tabular}{|c|c|c|c|c|c|c|c|}
\hline Temperature $\left[{ }^{\circ} \mathbf{C}\right]$ & $\Delta \mathbf{H}[\mathbf{J} / \mathbf{g}]$ & $\mathbf{R P M} \boldsymbol{\alpha}[\boldsymbol{\%}]$ & $\mathbf{I}_{\mathbf{t}}[\mathbf{s}]$ & $\mathbf{t}_{\mathbf{g}}[\mathbf{s}]$ & $\mathbf{k}\left[\mathbf{m i n}^{-\mathbf{1}}\right]$ & $\boldsymbol{\alpha}_{\mathbf{f}} \cdot \mathbf{1 0 0}[\boldsymbol{\%}]$ & $\mathbf{R}_{\mathbf{p m a x}}\left[\mathbf{m i n}^{-\mathbf{1}}\right]$ \\
\hline 25 & $58 \pm 4$ & $6.3 \pm 0.3$ & $2.9 \pm 0.1$ & 4.8 & $10.3 \pm 0.2$ & 30 & $1.8 \pm 0.1$ \\
\hline 35 & $95 \pm 6$ & $8.9 \pm 0.3$ & $1.8 \pm 0.1$ & 3.6 & $14.8 \pm 0.2$ & 40 & $3.2 \pm 0.1$ \\
\hline 45 & $160 \pm 10$ & $12.1 \pm 0.5$ & $1.6 \pm 0.1$ & 3.4 & $18.1 \pm 0.3$ & 80 & $4.2 \pm 0.1$ \\
\hline 55 & $170 \pm 10$ & $14.1 \pm 0.7$ & $1.3 \pm 0.1$ & 3.0 & $21.4 \pm 0.3$ & - & - \\
\hline 65 & $168 \pm 10$ & $13.0 \pm 0.7$ & $1.2 \pm 0.1$ & 2.8 & $24.8 \pm 0.3$ & 99 & $5.8 \pm 0.1$ \\
\hline
\end{tabular}

( $\triangle H$ enthalpy, $R P M$ resin reacted at peak maximum, $I_{t}$ induction time, $t_{g}$ gel time, $k$ coefficient of rate, $\alpha_{f} \times 100$ degree of conversion, $R_{p}$ rate of polymerization)

Table 3. Effect of measurement temperature on kinetic parameters, @ $I=3.3 \mathrm{~mW} / \mathrm{cm}^{2}$, for Riston ${ }^{\circledR} \mathrm{PM} 215$

\begin{tabular}{|c|c|c|c|c|c|c|c|}
\hline Temperature $\left[{ }^{\circ} \mathbf{C}\right]$ & $\Delta \mathbf{H}[\mathbf{J} / \mathbf{g}]$ & $\mathbf{R P M} \boldsymbol{\alpha}[\boldsymbol{\%}]$ & $\mathbf{I}_{\mathbf{t}}[\mathbf{s}]$ & $\mathbf{t}_{\mathbf{g}}[\mathbf{s}]$ & $\mathbf{k}\left[\mathbf{m i n}^{\mathbf{- 1}}\right]$ & $\boldsymbol{\alpha}_{\mathbf{f}} \cdot \mathbf{1 0 0}[\boldsymbol{\%}]$ & $\mathbf{R}_{\mathbf{p m a x}}\left[\mathbf{m i n}^{-\mathbf{1}}\right]$ \\
\hline 25 & 62 & $9.6 \pm 0.3$ & $1.8 \pm 0.1$ & 3.6 & $16.8 \pm 0.2$ & 40 & $3.6 \pm 0.1$ \\
\hline 35 & 76 & $10.0 \pm 0.3$ & $1.5 \pm 0.1$ & 3.0 & $20.4 \pm 0.3$ & 45 & $4.8 \pm 0.1$ \\
\hline 45 & 119 & $12.3 \pm 0.5$ & $1.3 \pm 0.1$ & 2.8 & $22.6 \pm 0.3$ & 55 & $6.0 \pm 0.1$ \\
\hline 55 & 175 & $13.7 \pm 0.5$ & $1.2 \pm 0.1$ & 2.6 & $25.9 \pm 0.3$ & 85 & $7.0 \pm 0.1$ \\
\hline 65 & 266 & $15.1 \pm 0.7$ & $1.1 \pm 0.1$ & 2.6 & $30.4 \pm 0.3$ & 99 & $7.2 \pm 0.1$ \\
\hline
\end{tabular}

( $\triangle H$ enthalpy, $R P M$ resin reacted at peak maximum, $I_{t}$ induction time, $t_{g}$ gel time, $k$ coefficient of rate, $\alpha_{f} \times 100$ degree of conversion, $R_{p}$ rate of polymerization)

The examination of Tables 2 and 3 shows that generally the increase in the temperature contributes more reactivity in both samples $(\Delta H, k, \alpha$ increase with the temperature and $I_{t}$ and gel time $t_{g}$ decreasing when the temperature increases). Riston ${ }^{\circledR}$ PM 215 is more reactive across all temperatures except at $65^{\circ} \mathrm{C}$, at which similar reactivity were observed (close $\alpha$ and $I_{t}$ ).

It should be highlighted that at higher temperatures the period of induction is less significant. It is thus necessary to determine an optimum temperature for each type of photoresist to obtain a good polymerization. Our study locates this temperature to be $65^{\circ} \mathrm{C}$, at which the conversion rate is $99 \%$.

The influence of the temperature also gives access the energy of activation while following the evolution of the coefficient rate $k$ as a function of $10^{3} / T$ according to the expression $\ln k=\ln Z-E_{\text {has }} / R T$. We represented on Figure 1 these variations, in semi-logarithmic scale, $T$ is the temperature of measurement. One reaches easily the value of the energy of $E_{a}$ activation of the reaction of polymerization of the two types of Riston ${ }^{\circledR}$ thanks to the slope of these lines. The value of $E_{a}$ is about $(17.7 \pm 0.5) \mathrm{kJ} / \mathrm{mol}$ and $(11.7 \pm 0.5) \mathrm{kJ} / \mathrm{mol}$ respectively for Riston ${ }^{\circledR}$ MM 140 and Riston ${ }^{\circledR}$ PM 215. As the activation energy of Riston ${ }^{\circledR}$ PM 215 is lower than the Riston ${ }^{\circledR}$ MM 140, it appears that the conversion of the Riston ${ }^{\circledR}$ PM 215 is easier than that of the Riston ${ }^{\circledR}$ MM 140, which confirms the superior photosensitivity of the Riston ${ }^{\circledR}$ PM 215.

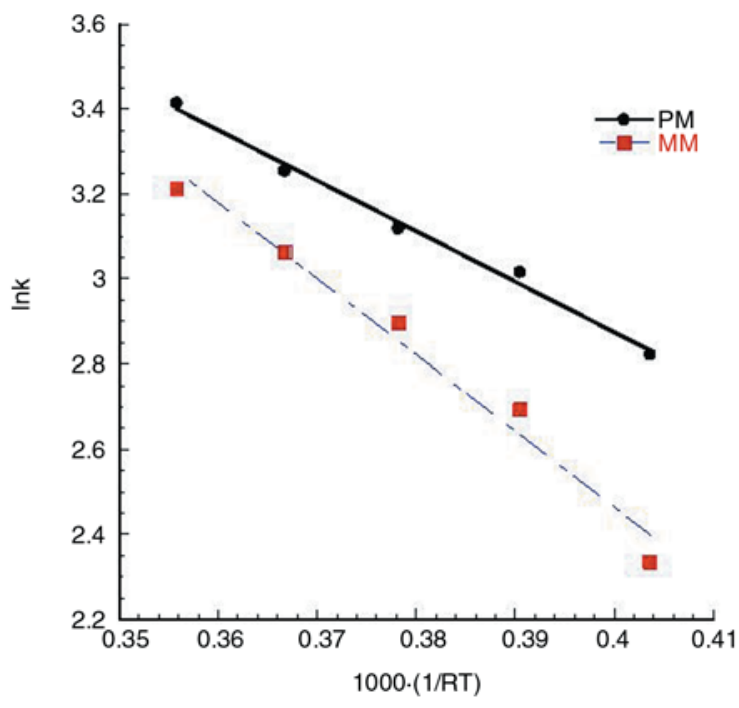

Figure 1. Variation of $\ln k$ as function of temperature of measurement (Riston ${ }^{\circledR}$ PM 215, Riston ${ }^{\circledR}$ MM 140)

\subsection{Others kinetic parameters}

The photoreactivity of Riston ${ }^{\circledR}$ photoresists through the polymerisation speed and the conversion rate under UV will be analyzed.

\subsubsection{Degree of conversion}

Figures 2 and 3 present the evolution of the conversion rate $\alpha$ according to the time of irradiation of Riston ${ }^{\circledR}$ MM 140 and Riston ${ }^{\circledR}$ PM 215 respectively for $I=3.3 \mathrm{~mW} / \mathrm{cm}^{2}$. 


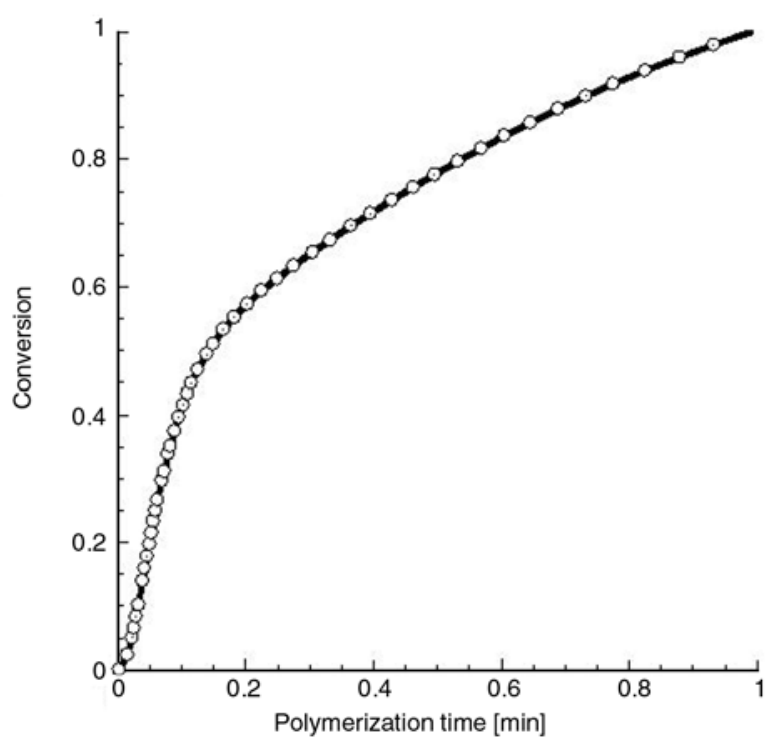

Figure 2. Evolution of conversion rate as function of irradiation time, for Riston ${ }^{\circledR} \mathrm{MM} 140$, at $T=65^{\circ} \mathrm{C}$ and $I=3.3 \mathrm{~mW} / \mathrm{cm}^{2}$

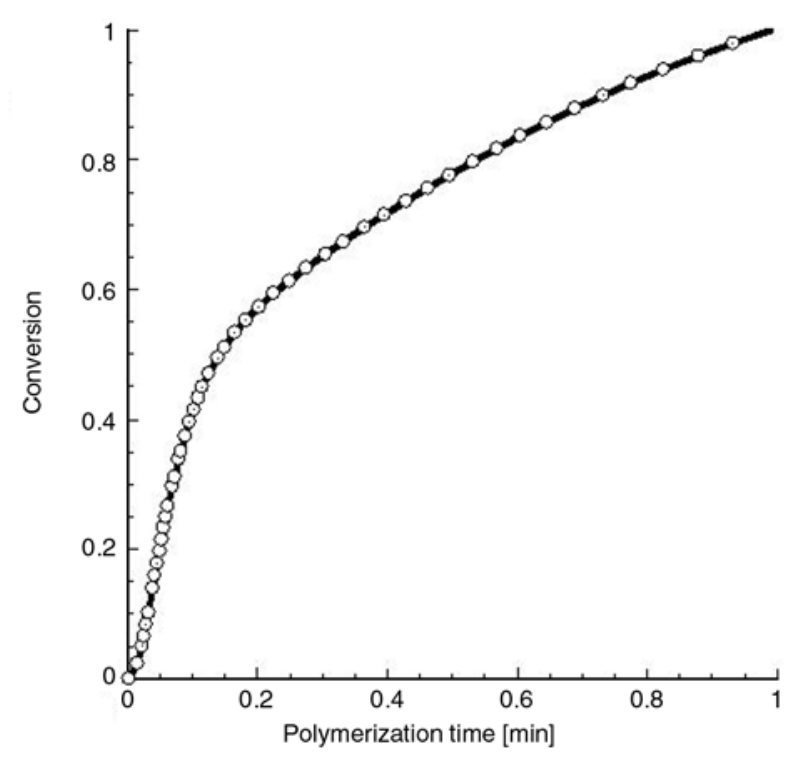

Figure 3. Evolution of conversion rate as function of irradiation time, for Riston ${ }^{\circledR} \mathrm{PM} 215$, at $T=65^{\circ} \mathrm{C}$ and $I=3.3 \mathrm{~mW} / \mathrm{cm}^{2}$

Rate of photoconversion of 58 and $65 \%$ of Riston ${ }^{\circledR}$ MM 140 and Riston ${ }^{\circledR}$ MP 215 respectively, are reached after $12 \mathrm{~s}$ of irradiation. The rate of $98 \%$ of conversion is obtained at the end of $54 \mathrm{~s}$ of irradiation for sample Riston ${ }^{\circledR}$ MM 140 and 48 s for sample Riston ${ }^{\circledR}$ PM 215. Although the two samples have a good photoreactivity, that of Riston ${ }^{\circledR}$ PM 215 is superior.

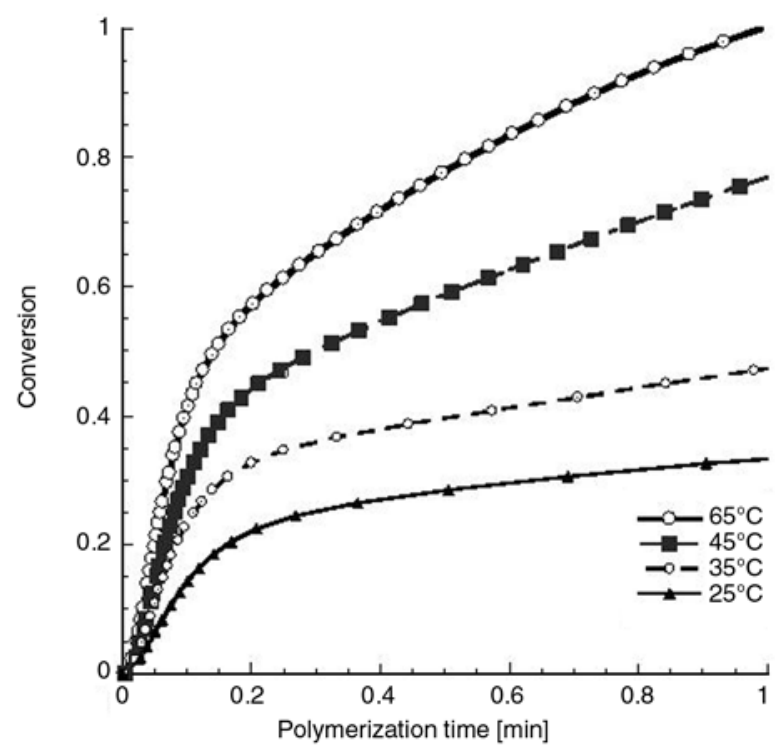

Figure 4. Evolution of conversion rate as a function of polymerization time at different temperatures (Ristons ${ }^{\circledR}$ MM 140, $I=3.3 \mathrm{~mW} / \mathrm{cm}^{2}$ )

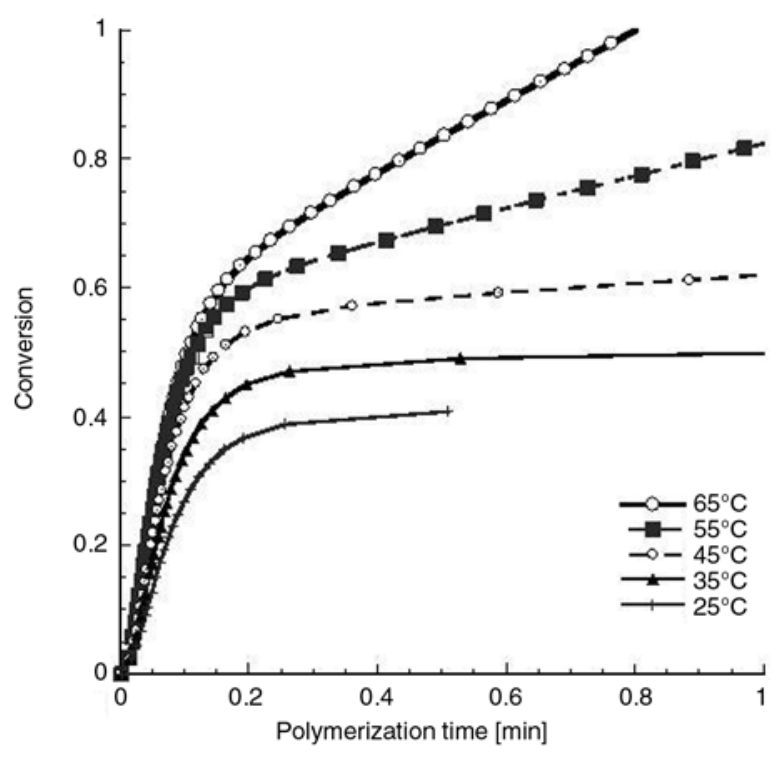

Figure 5. Evolution of conversion rate as a function of polymerization time at different temperatures (Ristons ${ }^{\circledR}$ PM 215, $I=3.3 \mathrm{~mW} / \mathrm{cm}^{2}$ )

\subsubsection{Effect of the temperature}

The influence of the temperature of measurement on the photoconversion, under irradiation intensity $I=3.3 \mathrm{~mW} / \mathrm{cm}^{2}$ is illustrated in Figures 4 and 5 (the experimental conditions are the same for all temperatures).

For the Riston ${ }^{\circledR}$ MM 140 (Figure 4), at the end of one minute reaction, the rate of photoconversion is 33, 46 and $77 \%$ when the temperature increases from 25 to 35 and $45^{\circ} \mathrm{C}$ respectively. And finally conversion is quasi complete at $65^{\circ} \mathrm{C}$. 
With regards to the Riston ${ }^{\circledR}$ PM 215, Figure 5 shows that the limiting conversion rate of $40 \%$ is reached upon $30 \mathrm{~s}$ of irradiation at $25^{\circ} \mathrm{C}$. When temperature increases from 35 to $55^{\circ} \mathrm{C}$, the conversion rate, at the end of one minute of irradiation, is respectively 50,62 and $82 \%$. The quasi complete consumption of the double bonds $\mathrm{C}=\mathrm{C}$ (since the resists contain a significant amount of multifunctional acrylate) is observed at $65^{\circ} \mathrm{C}$ upon $48 \mathrm{~s}$ irradiation.

Moreover, the curves representing the evolutions of the rate of photoconversion indicate that the temperature of polymerization play a significant role in the kinetics of the crosslinking polymerization of Ristons $^{\circledR}$. Indeed, when the temperature of measurement is high, the reactive species benefit from a larger kinetic energy and an improved mobility. The period of induction is less significant and the values of the limiting rate of photoconversion are sufficiently high to predict a complete reticulating polymerization samples.

\subsubsection{Effect of intensity I of irradiation}

The effect of irradiation intensity on the conversion rate is analyzed at the temperature $T=65^{\circ} \mathrm{C}$ (temperature inducing the optimum value of the kinetic parameters).

For both samples the curves have the same slope:

- fast increase in the conversion rate from the very start of the exposure:

for Riston ${ }^{\circledR}$ PM 215, during this period, the conversion rate is independent of the intensity during the 9 first second of the exposition (at $9 \mathrm{~s}, \alpha=58 \%$ regardless of the intensity $I$ );

- increase much slower at the end of the exposure. The influence of the irradiation intensity increases with the exposition time. For the most reactive Riston ${ }^{\circledR}$ PM 215, conversion rates of $100 \%$ is obtained at the end of $49 \mathrm{~s}$ with an intensity of $I=$ $3.3 \mathrm{~mW} / \mathrm{cm}^{2}$ while the conversion rate is only $90 \%$ at the end of one minute with an intensity of $I=$ $2.2 \mathrm{~mW} / \mathrm{cm}^{2}$. The increase in intensity $I$ is accompanied by an increase in the conversion rate throughout the process of crosslinking reaction. This result is justified by the fact that combined effects of the temperature, which increases the mobility of the reactive species and the intensity of the irradiation which breaks the bonds $\mathrm{C}=\mathrm{C}$, makes the medium more favourable. Decker (1996) showed that the luminous flow of excitation plays a

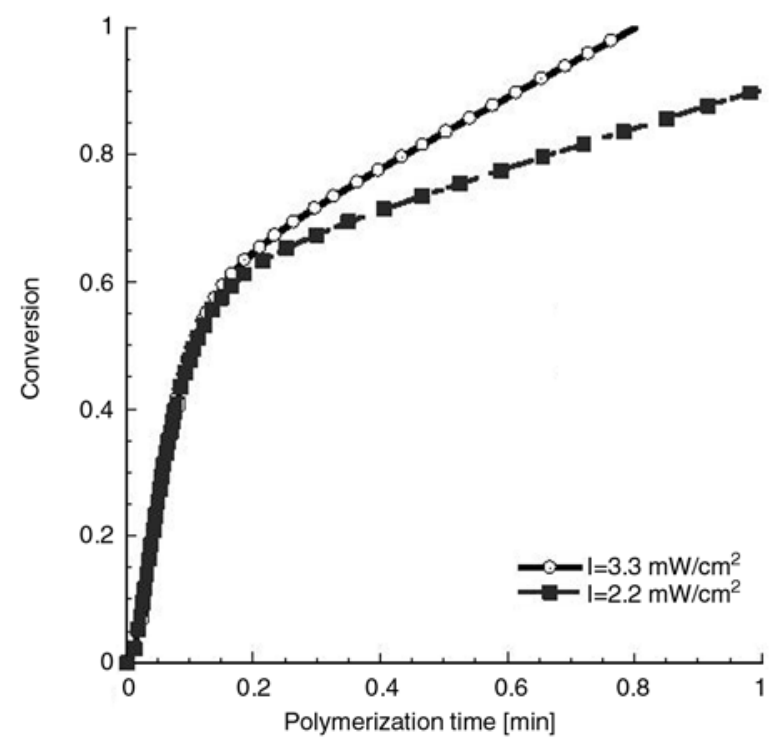

Figure 6. Influence of intensity $I$ on conversion rate at $T=65^{\circ} \mathrm{C}, I=3.3$ et $I=2.2 \mathrm{~mW} / \mathrm{cm}^{2}$ (Riston $^{\circledR}$ PM 215)

dominating role in the reactions of polymerization process; it acts by its wavelength, its intensity and its homogeneity. Quantum yield being related to the intensity of the irradiation, Figure 6 shows clearly that any increase in the light intensity of radiation UV involves an increase proportional in limiting conversion and in parallel a reduction in the period of induction is observed (see Table 1).

The curves of photoconversion (Figures 7 and 8) clearly exhibit that Riston ${ }^{\circledR}$ PM 215 has a rate of crosslinking higher than Riston ${ }^{\circledR}$ MM 140 for identical experimental conditions.

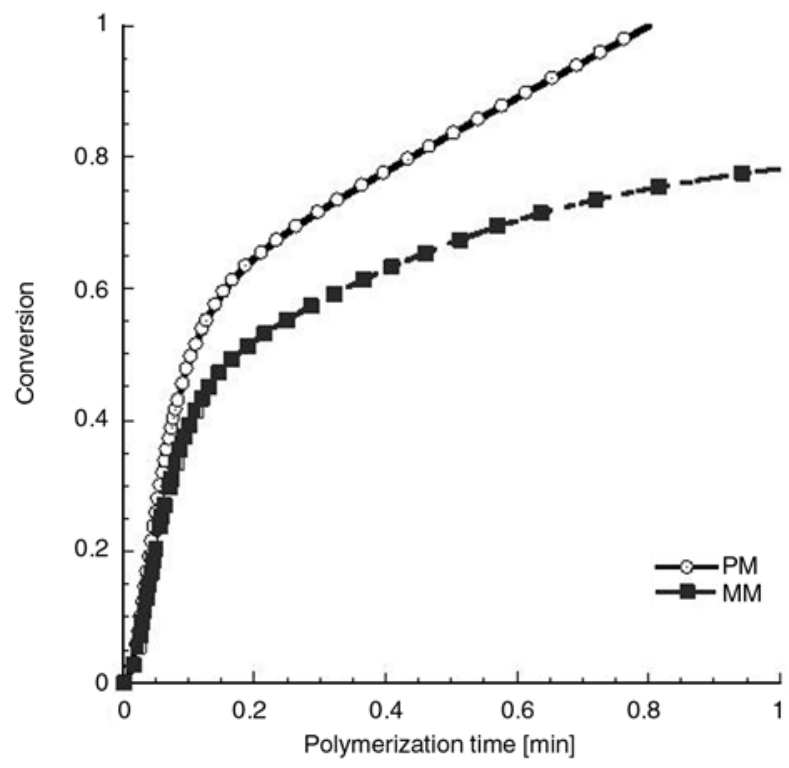

Figure 7. Comparison of conversion rate evolution during polymerization of the two Ristons ${ }^{\circledR}$ $\left(I=3.3 \mathrm{~mW} / \mathrm{cm}^{2}\right.$ and $\left.T=65^{\circ} \mathrm{C}\right)$ 


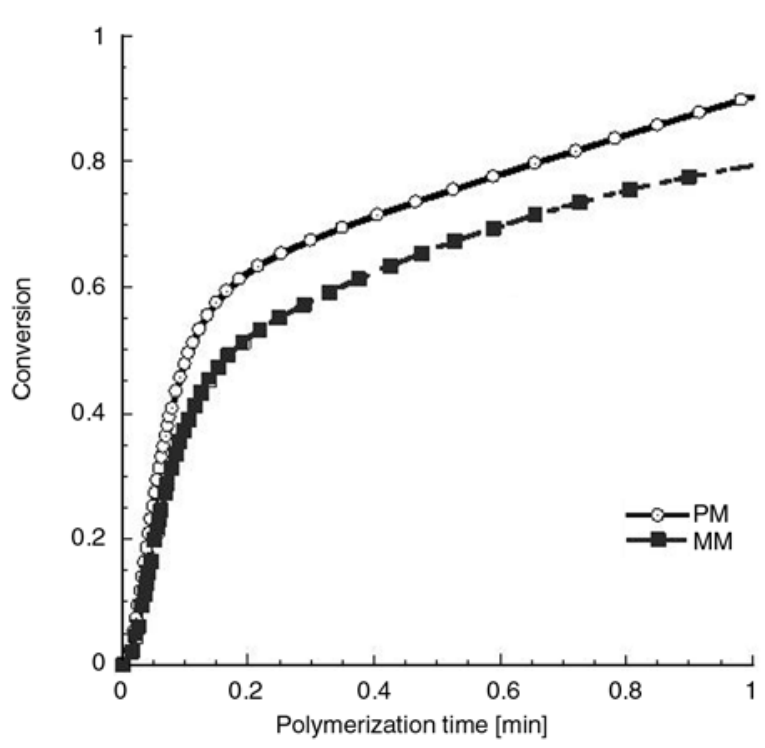

Figure 8. Comparison of conversion rate evolution during polymerization of the two Ristons ${ }^{\circledR}$ $\left(I=2.2 \mathrm{~mW} / \mathrm{cm}^{2}\right.$ and $\left.T=65^{\circ} \mathrm{C}\right)$

From the two samples, the Riston ${ }^{\circledR}$ PM 215 is most reactive. It is may be an intrinsic property which is due to its composition and its structure.

This observation is also emphasized regardless of the temperature of measurement and the intensity of the irradiation.

The effect of the temperature shows that the conversion rate is maximum at $T=65^{\circ} \mathrm{C}$. We also observed that the irradiation time necessary to obtain a maximum conversion rate is one minute (1 min).

The irradiation intensity of $I=3.3 \mathrm{~mW} / \mathrm{cm}^{2}$ is sufficient and induces a larger conversion rate.

These curves highlight the influence of the nature of the resist on the kinetic profile. Indeed it appears clearly that the values of final conversion (estimated approximately at the end of a minute of reaction) depend primarily on the formulation or basic composition of the resist. Thus in the case of the system PlateMaster 100 conversion proves to be almost complete (value of final conversion near to $100 \%$ ) whereas this value is $80 \%$ for the system MultiMaster 100. The remarkable reactivity of PlateMaster 100 is probably due to its composition: the functionality of the monomer, the nature of the initiators and activators. If we examine the kinetic profile of the two systems closely, we notice that it is the same during the first three seconds of the reaction. That highlights the importance of the mobility of the polymeric radicals in growth and the density of the formed polymeric network.

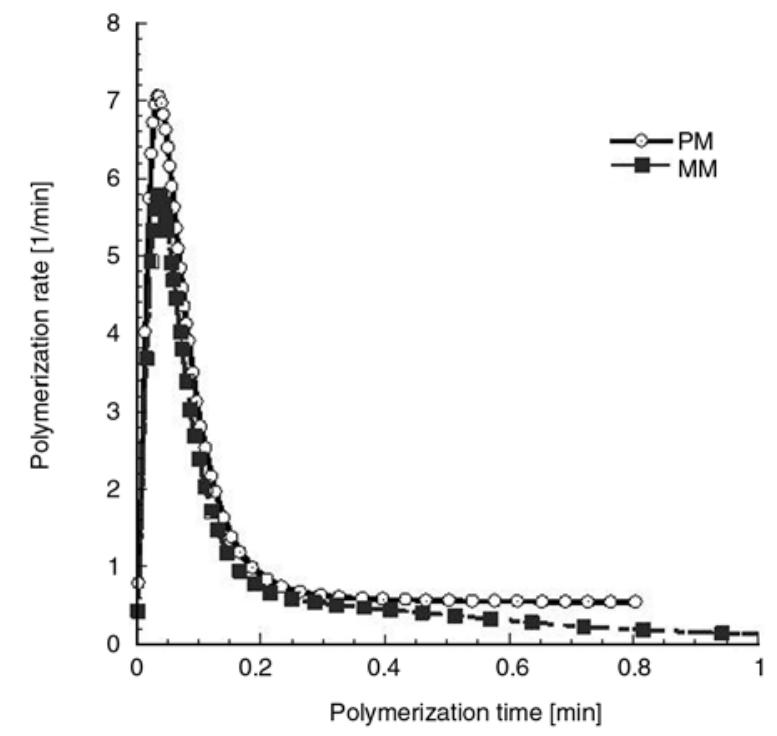

Figure 9. Comparison of conversion rate evolution during polymerization of the two Ristons ${ }^{\circledR}\left(T=65^{\circ} \mathrm{C}\right.$ and $I=3.3 \mathrm{~mW} / \mathrm{cm}^{2}$ )

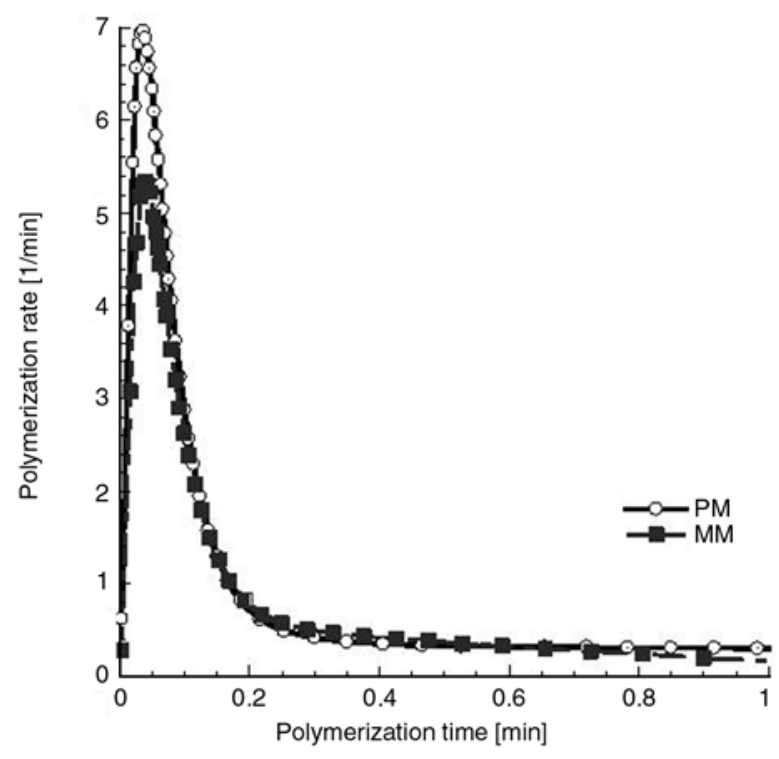

Figure 10. Comparison of conversion rate evolution during polymerization of the two Ristons ${ }^{\circledR}$ $\left(T=65^{\circ} \mathrm{C}\right.$ and $\left.I=2.2 \mathrm{~mW} / \mathrm{cm}^{2}\right)$

\subsection{Photopolymerization rate}

Figures 9 and 10 represent the evolution of polymerization rate as function of irradiation time for the two samples studied at both intensity $I=$ $3.3 \mathrm{~mW} / \mathrm{cm}^{2}$ and $I=2.2 \mathrm{~mW} / \mathrm{cm}^{2}$.

The photopolymerization, of the two samples, begins with a maximum rate which decreases quickly. The maximum value, reached at the end of $3 \mathrm{~s}$, is $5.80 \mathrm{~min}^{-1}$ for Riston ${ }^{\circledR} \mathrm{MM} 140$ and $7 \mathrm{~min}^{-1}$ for Riston ${ }^{\circledR}$ PM 215. The larger reactivity of Riston ${ }^{\circledR}$ PM 215 is noticed here. 
The strong reactivity of Riston ${ }^{\circledR}$ PM 215 compared to Riston ${ }^{\circledR}$ MM 140 is highlighted by the maximum values of polymerization rate.

The crosslinking photoreaction of the two samples under UV exposure as a function of time indicates that the reaction was fast during the first second and then followed attenuation (Figure 9). It is very short even if the intensity of irradiation is relatively weak $\left(I=2.2 \mathrm{~mW} / \mathrm{cm}^{2}\right)$ and constitutes a major asset in the process of photolithography (Figure 10).

It appears clearly that the value of limiting polymerization rate also depends on the formulation or basic composition on the photoresist.

\section{Conclusions}

The kinetics of reticulation of negative photoresists allowed, by differential photocalorimetry with compensation of power (DPC), the quantification of a certain number of significant parameters such as enthalpy of polymerization, induction time, coefficient of rate, activation energy and the conversion rate.

We examined the effect of irradiation intensity and temperature on several kinetic parameters $(\Delta H$, $\left.k, I_{t}\right)$, conversion to the reacted maximum peak (RPM), the degree of conversion $\alpha$ and the polymerization rate $R_{p}$.

The values of these kinetic parameters $\left(\Delta H, k, I_{t}\right.$ and RPM) indicate that Riston ${ }^{\circledR}$ PM 215 presents a stronger photoreactivity compared to Riston ${ }^{\circledR}$ MM 140, probably due to the difference in the chemical structure of the acrylates used. Increasing the intensity increases the photoconversion throughout the polymerization process for the two samples. While monitoring, by DPC, the evolution of the photoconversion of irradiated film, one finds a kinetic curve representing an almost complete conversion. The high values of the limiting conversion rate and the polymerization rate show that the reactivity of both the radical initiators and monomers in the formulation of these two samples is very significant.
The photoconversion is not only quasi-instantaneous but also completes at temperature $T=65^{\circ} \mathrm{C}$; this value would thus be indicated during the irradiation in the microlithographic process.

Although at $T=65^{\circ} \mathrm{C}$ the two samples have similar reactivities, the low value of the energy of activation is obtained for Riston ${ }^{\circledR}$ PM 215 attesting that the conversion of this Riston ${ }^{\circledR}$ is easier and confirms its strong photosensitivity compared to Riston ${ }^{\circledR}$ MM 140.

All kinetic parameters studied emphasized the strong photoreactivity of Riston ${ }^{\circledR}$ PM 215. The photosensitivity of the Riston ${ }^{\circledR}$ PM 215 is better than Riston ${ }^{\circledR}$ MM 140 and hence makes it more suitable for an efficient microlithography.

We believe that the new generation of Riston ${ }^{\circledR}$ PM 215 is more powerful on the kinetic level for an etching. Our study recommends its formulation to the industrials and to manufacturers of printed circuits with the following conditions for optimum performance: an irradiation of intensity $I=$ $3.3 \mathrm{~mW} / \mathrm{cm}^{2}$ at the temperature $T=65^{\circ} \mathrm{C}$.

\section{References}

[1] Brainard R., Baeclay G. G., Anderson E. H., Ocola L. E.: Resists for next generation lithography. Microelectronic Engineering, 61-62, 707-715 (2002).

[2] Kukharenka E., Farooqui M. M., Grigore L., Kraft M., Hollinshead N.: Electroplating moulds using dry film thick negative photoresist. Journal of Micromechanics and Microengineering, 13, 67-74 (2003).

[3] Shaw J. M., Gelorme J. G., LaBianca N. C., Conley W. E., Holmes S. J.: Negative photoresists for optical lithography. Journal of Research and Development, Optical Lithography, 41, 81-94 (1997).

[4] de Almeida Y. B. M., Carrera L. C. M., Abadie M. J. M.: Photopolymerization of multifunctional acrylates MAM using trans-10,11-dibromodibenzosuberone as radical photoinitiator. European Polymer Journal, 32, 1355-1360 (1996).

[5] Sestak J., Berggren G.: Study of the kinetics of the mechanism of solid-state reactions at increasing temperatures. Thermochimica Acta, 3, 1-12 (1971). 